\title{
Control of Flowering and Runnering in Strawberry
}

\author{
Timo Hytönen ${ }^{1,2,3 *}$ and Takeshi Kurokura ${ }^{4}$
}

\author{
${ }^{1}$ Department of Agricultural Sciences, Viikki Plant Science Centre, University of Helsinki, Latokartanonkaari 7, 00790 Helsinki, \\ Finland \\ ${ }^{2}$ Organismal and Evolutionary Biology Research Programme, Faculty of Biological and Environmental Sciences, Viikki Plant \\ Science Centre, University of Helsinki, Viikinkaari 1, 00790 Helsinki, Finland \\ ${ }^{3}$ NIAB EMR, Kent ME19 6BJ, United Kingdom \\ ${ }^{4}$ Faculty of Agriculture, Utsunomiya University, Utsunomiya 321-8505, Japan
}

Strawberry flowering physiology has engaged the interest of researchers for almost a century after the initial reports demonstrating the photoperiodic control of flowering and vegetative reproduction through stolons called runners. Most strawberries possess a seasonal flowering habit with flower initiation occurring under short days in autumn and flowering during the following spring. Also perpetual flowering genotypes are known in diploid woodland strawberry (Fragaria vesca $L_{\text {. }}$ ) and octoploid garden strawberry $(F$. $\times$ ananassa Duch.), and recent research have shown that this trait has evolved independently in different species. Studies in the perpetual flowering mutant of woodland strawberry led to the identification of TERMINAL FLOWER1 (FvTFL1) as a major floral repressor causing the seasonal flowering habit in this species and demonstrated that recessive mutation in this gene leads to perpetual flowering. This breakthrough opened an avenue for molecular understanding on the control of flowering by different environmental signals. Different loci control perpetual flowering in garden strawberry including one dominant major locus and additional environmentally regulated epistatic loci. The major gene is called Perpetual Flowering Runnering (PFRU) because it also reduces the number of runners. Growth regulator applications initially demonstrated the role of gibberellin in the control of runner formation, and molecular understanding on the role of gibberellin biosynthesis and signaling in this process has started to emerge. Here, we present current understanding and major open questions on the control of flowering and runnering in strawberries. In order to understand the control of flowering in the context of perennial growth cycle, we also discuss current knowledge on the control of dormancy.

Key Words: Fragaria, genetics, growth cycle, molecular mechanism, reproduction.

\section{Introduction}

Garden strawberry (Fragaria $\times$ ananassa Duch.) is the most economically important berry crop in the world with the total production of 12.8 million tons in 2016 (FAOstat). Strawberries are grown in all continents from tropical areas to sub-arctic climates demonstrating the ability of the species to adapt to different environments (Simpson, 2018). Control of flowering is one of the key processes that determines the ability of the species to adapt to different climates and growing

Received; November 28, 2019. Accepted; February 3, 2020.

First Published Online in J-STAGE on April 6, 2020.

Special Issue "Strawberry".

* Corresponding author (E-mail: timo.hytonen@helsinki.fi). conditions. Especially the Californian strawberry industry has facilitated the expansion of the strawberry production into warmer areas by introducing new alleles of flowering genes from wild parental species F. virginiana ssp. glauca (Bringhurst and Voth, 1981; Ahmadi et al., 1990; Hardigan et al., 2018). Additional gene pools are available in the wild populations of $F$. virginiana and $F$. chiloensis that is the other octoploid parent of the garden strawberry as well as in the populations of their reported diploid progenitors including F. iinumae, F. nipponica, F. viridis, and broadly distributed woodland strawberry, F. vesca (Liston et al., 2014; Hilmarsson et al., 2017; Edger et al., 2019). These can be harnessed in cultivar breeding by using marker assisted selection of allelic variation existing in current breeding materials, introgressions from octo- 
ploid species, or genome editing technologies.

Strawberries are perennial plants that form a determinate inflorescence from the apical meristem of the leaf rosette. Their axillary meristems can differentiate into either branch crowns (axillary leaf rosette) that are able to bear additional inflorescences or stolons called runners that enable vegetative reproduction. Because of these alternative fates of axillary meristems, there is a strong trade-off between flowering and runnering (Heide et al., 2013; Costes et al., 2014). This trade-off is commercially important in garden strawberry because the number of inflorescences depends on the number of branch crowns (Hytönen et al., 2004), and on the other hand, runners are needed for clonal propagation of the crop.

Strawberries can be roughly categorized into two groups; seasonal flowering strawberries that are also called June-bearing or once-flowering plants, and perpetual flowering types that are called everbearing, remontant, repeat flowering or day-neutral plants in different reports. Environmental responses of different types have been studied for decades in both garden strawberry and woodland strawberry, and various responses have been reported in different cultivars and genotypes. These studies have been extensively reviewed by Heide et al. (2013), but in general, seasonal flowering strawberries are short-day (SD) plants that initiate terminal flower buds in autumn, and inflorescences emerge from overwintered buds following spring. In perpetual flowering genotypes, in contrast, long days (LD) typically promote flowering that can continue the whole growing season. In both types, the photoperiodic responses exhibit various degree of temperature-dependence that can be important for adaptation to climate change, local growing conditions, and different production systems (e.g. Heide, 1977; Sønsteby and Heide, 2007a; Bradford et al., 2010).

Molecular studies have mostly focused on the control of flowering in woodland strawberry (e.g. Koskela et al., 2012; Mouhu et al., 2013; Kurokura et al., 2017). However, due to year-round demand of fresh berries, a lot of research have recently been focusing on the genetic basis of perpetual flowering in garden strawberry (e.g. Gaston et al., 2013; Lewers et al., 2019), but the molecular mechanism controlling this trait in cultivars is unknown. Here we present a synthesis on the research on the control of flowering in strawberries and try to elaborate current knowledge and research needs on the molecular basis and evolution of different response types. In addition, we discuss the control of strawberry plant architecture that is critical for the success of commercial strawberry production. In order to understand the control of flowering in the context of perennial growth cycle, also current knowledge on the control of dormancy is presented.

\section{Environmental Control of Flowering}

Already in 1930's, Darrow and Waldo (1934) have reported that seasonal flowering cultivars of the garden strawberry require either SDs or cool temperatures for flower induction, while perpetual flowering cultivars are LD plants. Seasonal flowering SD cultivars are typically induced to flower under day lengths shorter than 12-14 h (Darrow and Waldo, 1934; Ito and Saito, 1962; Heide, 1977; Verheul et al., 2007). Cool temperature $\left(9^{\circ} \mathrm{C}\right)$ has been found to complement this SD requirement especially in some north-adapted early flowering cultivars, but some cultivars do not exhibit this temperature response (Heide, 1977; Sønsteby and Heide, 2006). High temperatures above $\sim 24^{\circ} \mathrm{C}$ typically prevent SD-induction of flowering, but variation between cultivars has been observed (Ito and Saito, 1962; Heide, 1977; Bradford et al., 2010; Sønsteby and Heide, 2017). Temperature affects also flower initiation, and according to several reports, optimal temperature for flower initiation is between $15-19^{\circ} \mathrm{C}$ (Le Mière et al., 1996; Manakasem and Goodwin, 2001; Sønsteby and Heide, 2008).

Although perpetual flowering cultivars have been classified as LD plants in initial studies (Darrow and Waldo, 1934; Downs and Piringer, 1955), more recent cultivars that originate from crosses between garden strawberry and F. virginiana ssp. glauca accessions from the Wassatch Mountains in Utah have been reported as day-neutral plants (Durner et al., 1984). Several later studies, however, have confirmed that LDs promote flowering in these cultivars especially at high temperatures (Serçe and Hancock, 2005; Sønsteby and Heide, 2007a, b; Bradford et al., 2010). High temperature can cause reversion from generative to vegetative stage especially in SDs (Nishiyama and Kanahama, 2000; Nishiyama et al., 2003; Sønsteby and Heide, 2007b), and it is one possible reason for severe crop losses reported in UK and USA after the periods of unusually high temperatures (Dale et al., 2002; Wagstaffe and Battey, 2006). To tackle this problem, genetic variation in heat tolerance has been found in the Honeoye $\times$ Tribute $F_{1}$ progeny (Mookerjee et al., 2013), and elite perpetual flowering breeding material with better heat tolerance has been developed (Hancock et al., 2018). One particularly interesting phenotype in perpetual flowering progenies is that they typically produce flowers in young runner tips (Ahmadi et al., 1990), a phenotype that has not been reported in seasonal flowering strawberries.

Very clear environmental responses are found in the diploid woodland strawberry that provides an excellent model system to explore molecular control of flowering. In seasonal flowering genotypes, SD-induction of flowering takes place at temperatures of $\sim 13-20^{\circ} \mathrm{C}$, while cooler temperatures induce flowering independently of the photoperiod, and higher temperatures 
prevent floral development (Heide and Sønsteby, 2007; Rantanen et al., 2015). Perpetual flowering mutants, in contrast, are LD plants. At $18-22^{\circ} \mathrm{C}$, seedlings grown under $18 \mathrm{~h}$ LDs flower very early, after producing 5-7 leaves in the primary leaf rosette, while $12 \mathrm{~h} \mathrm{SD}$ conditions strongly delay flowering (Heide and Sønsteby, 2007; Mouhu et al., 2009; Kurokura et al., 2017). Similarly to seasonal flowering genotypes, perpetual flowering accessions become day-neutral at cool temperatures, and high temperatures cause strong inhibition of flowering in SDs (Heide and Sønsteby, 2007).

\section{Genetic Control of Flowering in Diploid Strawberries}

According to Darrow (1966), perpetual flowering mutants of woodland strawberry have been found from French Alps in 17th century. Brown and Wareing (1965) have demonstrated that this phenotype is caused by recessive alleles of a single locus, whereas the presence of a dominant allele leads to seasonal flowering. Using genetic mapping, two groups have identified 2bp deletion in the woodland strawberry homolog of TERMINAL FLOWER1 (FVTFL1) as a putative causal mutation for perpetual flowering trait (Iwata et al., 2012; Koskela et al., 2012), and the functional validation has been done by Koskela et al. (2012). Other crosses between Californian F. vesca and European perpetual flowering mutant suggest the presence of three dominant loci in the Californian genotype that can suppress the perpetual flowering trait (Ahmadi et al., 1990), but these putative floral repressors remain unknown. Additional QTLs controlling flowering time have been found in a NIL population with F. bucharica introgressions in the perpetual flowering cultivar 'Reine des Vallees' (Urrutia et al., 2015). One of these loci causes late flowering and is located on LG5, while another locus in the beginning of LG6 advances flowering. The third F. bucharica introgression on LG6 prevents flowering during the first season. Since FvTFL1 is located in this region in the woodland strawberry genome, these data indicate that F. bucharica TFL1 may complement the non-functional TFL1 alleles of 'Reine des Vallees' in this introgression line (Urrutia et al., 2015). Two more QTLs have been identified in a woodland strawberry $F_{2}$ mapping population using genotyping-by-sequencing (Samad et al., 2017). Finemapping and gene functional analyses are needed to identify causal genes.

\section{Genetic Control of Perpetual Flowering in the Garden Strawberry}

At least three different origins of perpetual flowering habit have been reported in garden strawberry including 1) old European cultivars originating from Gloede's seedling in 1866, 2) 'Pan American', a putative mutant of 'Bismarck' selected in New Your by S. Cooper in 1898, and 3) introgression from F. virginiana ssp. glauca accession collected from Wassatch mountains in Utah (Darrow, 1966; Bringhurst and Voth, 1981). The genetic basis of the two oldest origins are unknown, but several studies have focused on the genetic control of perpetual flowering in modern cultivars that include the Wassatch source in their pedigrees. Ahmadi et al. (1990) have reported 1:1 segregation ratios of seasonal vs perpetual flowering in several crosses of Californian breeding program indicating that a single dominant gene causes perpetual flowering in these populations. This dominant locus is able to cause perpetual flowering also in crosses between perpetual flowering garden strawberry and two Potentilla species (Ahmadi et al., 1990). Later, a range of segregation ratios and Gene $\times$ Environment interactions have been observed in a large number of populations suggesting a multi-gene model with one major locus for the control of perpetual flowering (Serçe and Hancock, 2005; Shaw and Famula, 2005).

Also the first QTL mapping study supports the multigene model in the expression of perpetual flowering habit including QTLs that are found only in specific environments (Weebadde et al., 2008). One major dominant QTL controlling perpetual flowering have been later identified in the linkage group IVb-f of the Capitola $\times \mathrm{CF} 1116 \mathrm{~F}_{1}$ population, and it is called Perpetual Flowering and Runnering (PFRU), because it also reduces the number of runners (Gaston et al., 2013). This locus is not orthologous with the genomic region containing FvTFL1 gene of woodland strawberry suggesting that different genes control this trait in diploid and octoploid strawberries (Gaston et al., 2013). Since the analysis of FaTFL1-RNAi lines has confirmed the function of FaTFL1 as a strong floral repressor in garden strawberry (Koskela et al., 2016), we hypothesize that PFRU is a strong floral activator that bypasses the repressive function of FaTFL1 to promote flowering. Several additional studies in different crossing populations have confirmed PFRU and narrowed down the locus (Castro et al., 2015; Honjo et al., 2016; Perrotte et al., 2016; Salinas et al., 2017; Verma et al., 2017; Hardigan et al., 2018). Causal gene has not been found, but several candidate genes have been suggested (Perrotte et al., 2016; Hardigan et al., 2018). Recent study, however, have shown that genetic markers closely associated with $P F R U$ do not provide reliable prediction of perpetual flowering habit in all crossing populations (Lewers et al., 2019). Segregation ratios found in this study suggest that at least two additional epistatic loci likely mediate environmental effects in different populations and can suppress perpetual flowering in progenies containing one or two dominant PFRU alleles (Fig. 1). Interestingly, one of these loci affects flowering only during the first season of the seedling suggesting that this locus becomes silenced during vernalization (Lewers et al., 2019). 


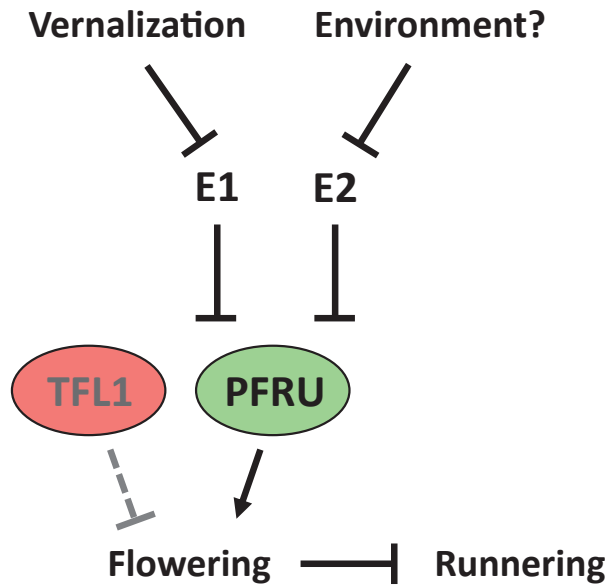

Fig. 1. Hypothetical model on the genetic control of flowering and runnering in perpetual flowering cultivars of the garden strawberry. PFRU is a dominant floral activator that bypasses the repressive function of FaTFL1. Two environmentally regulated epistatic loci (E1 and E2) control the activity of PFRU. Dominant PFRU alleles also suppress runnering indirectly, because flowering enforces the production of branch crowns instead of runners from axillary meristems. Arrows indicate activation and bars repression.

\section{Molecular Mechanisms of Flowering Time Control Are Emerging in Strawberries}

Control of flowering has been extensively studied in Arabidopsis (Andrés and Coupland, 2012; Cho et al., 2017), and these knowledge has greatly facilitated the identification of key flowering time genes in other species including strawberry (e.g. Koskela et al., 2012; Mouhu et al., 2013). One of these genes is TFL1 that encodes a major floral repressor in strawberries and many other rosaceous crops (Kotoda et al., 2006; Iwata et al., 2012; Koskela et al., 2012, 2016; Flachowsky et al., 2012; Freiman et al., 2012). In both woodland strawberry and Arabidopsis, TFL1 is expressed in meristematic tissues and its function is to maintain vegetative meristems (Bradley et al., 1997; Koskela et al., 2012). However, the developmental consequences of TFL1 expression are different because of different growth habits of these species. In Arabidopsis, the main function of TFL1 is to maintain vegetative inflorescence meristem that enables the production of indeterminate inflorescence (raceme), and it has only a minor effect on flowering time (Bradley et al., 1997). Woodland strawberry, in contrast, produces a determinate inflorescence (cyme), and the role of TFL1 homolog is to control vegetative to reproductive phase transition at the shoot apical meristem (Koskela et al., 2012).

According to molecular studies, seasonal cycling of FvTFL1 mRNA expression at the shoot apical meristem causes typical seasonal flowering habit of woodland strawberry (Koskela et al., 2012, 2017). In LDs of summer, high FvTFL1 mRNA level maintains the vegetative apical meristem, while the downregulation of the

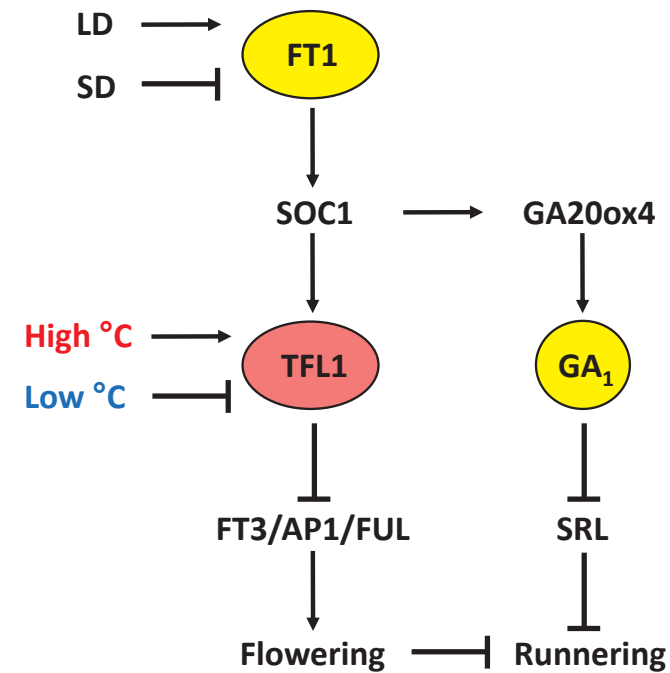

Fig. 2. Current model on the control of flowering and runnering in seasonal flowering woodland strawberry. A gene encoding a strong floral repressor FvTFL1 is regulated by photoperiodic signals (LD and $\mathrm{SD}=$ long and short day, respectively) mediated by FvFT1 through FvSOC1 and by ambient temperature through unknown mechanisms. FvSOC1 also promotes the biosynthesis of the active $\mathrm{GA}_{1}$ that stimulates runner formation through the degradation of SRL DELLA proteins. Arrows indicate activation and bars repression.

gene in autumn allows flower induction and initiation to take place. In the following spring, autumn-initiated inflorescences grow out, while the reactivation of FvTFL1 in newly formed branch crowns maintain vegetative meristems for the next seasonal cycle (Koskela et al., 2012, 2017). Recent studies have also demonstrated that FvTFL1 integrates both photoperiodic and temperature signals to control flower induction (Fig. 2). The downregulation of this gene by cool temperatures below $13^{\circ} \mathrm{C}$ or by SDs at temperatures of $13-20^{\circ} \mathrm{C}$ enables flower induction to occur, whereas the strong activation of FvTFL1 at higher temperatures prevents floral development (Rantanen et al., 2015). Functional differentiation has been found in Northern Norwegian woodland strawberry population in which long period of freezing temperatures is required for the silencing of FvTFL1, and flower induction and initiation takes place in the spring (Koskela et al., 2017).

Genes involved in the temperature regulation of FvTFL1 await to become elucidated, but the functional analysis of woodland strawberry homologs of $F L O W$ ERING LOCUS T (FvFTI) and SUPPRESSOR OF THE OVEREXPRESSION OF CONSTANS1 (FvSOC1) has shed some light into the photoperiodic control of FvTFL1 in seasonal flowering woodland strawberry (Koskela et al., 2012; Mouhu et al., 2013). All of these genes are activated in LDs, FvFT1 in leaves and FvSOC1 and FvTFL1 in shoot apices. The analysis of FvSOC1 RNAi and overexpression lines have confirmed that FvSOC1 represses flowering by activating FvTFL1 mRNA expression in seasonal flowering 
woodland strawberry (Mouhu et al., 2013). Furthermore, RNAi-silencing of FvFT1 in a tfll mutant 'Hawaii-4 (H4)' reduces the expression of FvSOCl in the shoot apex (Mouhu et al., 2013) supporting the model that leaf-expressed FvFT1 represses flowering by activating FvTFL1 at shoot apical meristem through FvSOC1. In this case, FvFT1 could be "a growthpromoting and flowering-inhibiting hormone" predicted by Guttridge (1959), but the functional analysis of FvFT1 in a genotype containing functional FvTFL1 is needed to confirm this hypothesis.

RNAi-silencing of FaTFL1 in 'Elsanta', the SD cultivar of the garden strawberry, has been found to cause perpetual flowering in LDs confirming that this gene encodes a major floral repressor also in this species (Koskela et al., 2016). In addition, the expression patterns of flowering time genes indicate that the genetic flowering pathway is at least partially conserved between diploid and octoploid strawberries (Nakano et al., 2015; Koskela et al., 2016). Actual flower induction is poorly understood in seasonal flowering strawberries, but the role of FvFT3 that is activated in the shoot apex in SDs before floral marker genes APETALA1 (FvAPl) and FRUITFULL (FvFUL) after the downregulation of FvTFL1 should be explored (Mouhu et al., 2009; Koskela et al., 2012, 2017; Nakano et al., 2015).

Photoperiodic flowering is better understood in the perpetual flowering mutant $\mathrm{H} 4$ that does not express functional FvTFL1 (Koskela et al., 2012). In H4, $F v F T 1$ is expressed in the leaves in flower-inductive LD conditions, and the silencing of this gene strongly delays flowering (Koskela et al., 2012; Kurokura et al., 2017). Furthermore, increasing FvFTI mRNA levels are associated with earlier flowering in various environmental conditions including different light qualities. End-of-day far-red light strongly promotes flowering in FvFT1-dependent manner, while red light has an opposite effect. Furthermore, blue light has only a weak promoting effect suggesting that phytochromes are major photoreceptors in the photoperiodic control of flowering in woodland strawberry (Rantanen et al., 2014). Functional analysis of FvCO (CONSTANS) has demonstrated its major role as an activator of $F v F T 1$ in leaves (Kurokura et al., 2017). However, comparison of diurnal gene expression rhythms of $F v C O$ and Arabidopsis $C O$ in $\mathrm{SD}$ and $\mathrm{LD}$ conditions shows that Arabidopsis external coincidence model is not directly applicable to woodland strawberry (Valverde et al., 2004; Fig. 3). In Arabidopsis, coincidence of $C O$ mRNA expression with light in LD afternoon leads to the activation of $F T$ in the evening (Suárez-López et al., 2001). Also in H4, FvFT1 exhibits a major peak in the evening in LDs and an additional peak $4 \mathrm{~h}$ after dawn, while $F v C O$ is highly expressed only at dawn (Kurokura et al., 2017). Despite of these differences in the mRNA expression rhythms, $\mathrm{FvCO}$ is required for both $F v F T 1$ expression peaks through an unknown

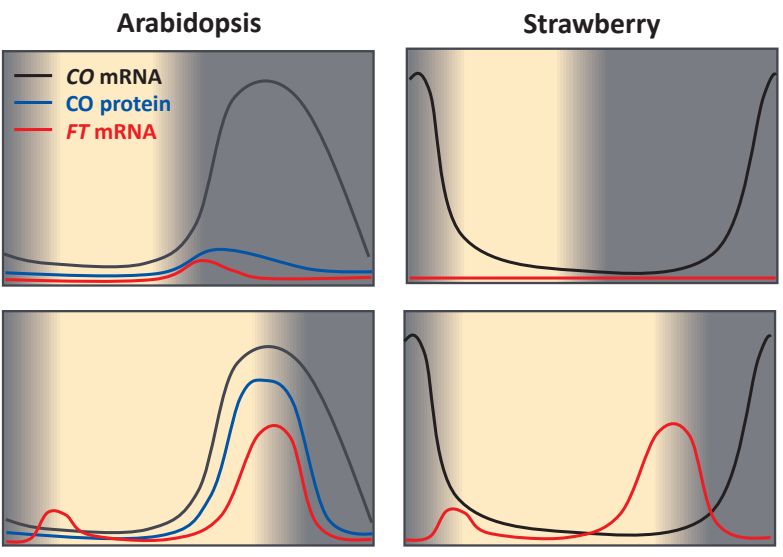

Fig. 3. Comparison of Arabidopsis and woodland strawberry $\mathrm{CO}$ FT modules in the control of flowering. In Arabidopsis, $C O$ mRNA starts to accumulate in late afternoon in both SDs and LDs. CO protein accumulates and activates $F T$ mRNA expression only in LDs when $C O$ mRNA expression coincide with light. In woodland strawberry, FvFT1 exhibits similar expression pattern than Arabidopsis FT, although the waveform of $\mathrm{CO}$ mRNA expression is different. No CO protein data is available in woodland strawberry.

mechanism. The finding that $F v F T 1$ expression is sensitive to photoperiod also in $F v C O$ overexpression lines suggests that $\mathrm{FvCO}$ activity is affected by light (Kurokura et al., 2017), possibly through stabilization of the protein as reported in Arabidopsis (Valverde et al., 2004).

Also additional putative floral regulators have been cloned. These include $F v G I$ (GIGANTEA) and FvFKFI (FALVIN-BINDING, KELCH REPEAT, F-BOX) that exhibit similar diurnal expression patterns with their Arabidopsis homologs (Sawa et al., 2007; Kurokura et al., 2017). Xiong et al. (2018) have reported 14 SPL (SQUAMOSA PROMOTER BINDING-LIKE) genes in woodland strawberry and explored their miR156 binding sites. Although tissue specific expression data has also been presented for both SPL genes and miR156, additional studies are needed to explore the role of these genes in the control of flowering in strawberries. One of these genes, FvSPL10 that is the close homolog with Arabidopsis floral activator SPL9 (Schwarz et al., 2008), is localized into nucleus, and according to in vitro and in vivo assays, it binds to FvAPI promoter to activate its expression (Xiong et al., 2019). Chen et al. (2018) has also identified 12 circadian clock genes and found rhythmic expression patterns comparable with Arabidopsis homologs, suggesting the conservation of the circadian clock genes between woodland strawberry and Arabidopsis.

\section{Control of Shoot Architecture in Strawberry}

Strawberry axillary meristem can form a runner, a branch crown or remain silent depending on a genotype, environmental conditions and developmental status of the shoot apical meristem. In general, 
environmental conditions that keep the plant in vegetative phase promote runner formation, while flowerinducing conditions increase the number of branch crowns (Hartmann, 1947; Konsin et al., 2001; Hytönen et al., 2004). After flower induction, axillary buds just below the primary inflorescence are destined to develop into branch crowns. These crowns may initiate additional inflorescences, which leads to additional crown branching and consumes axillary meristems that could produce runners causing a strong trade-off between flowering and runner formation (Hytönen et al., 2004; Kurokura et al., 2005). This trade-off is the most obvious in perpetual flowering cultivars that produce very few runners hampering the clonal propagation of the plants (Sønsteby and Heide, 2007a, b; Perrotte et al., 2016). The strong connection between runner formation and flower initiation also complicates studies on the direct effects of environment on axillary meristem fate. However, non-flowering FvTFL1 overexpression lines retain wild type photoperiodic responses in the control of axillary meristem fates confirming that direct photoperiodic regulation exists (Koskela et al., 2012).

Several lines of evidence have shown that gibberellin (GA) has a major role in the control of axillary meristem fate in strawberries. $\mathrm{GA}_{3}$ treatment induces runner formation in a runnerless mutant of woodland strawberry, and the inhibitors of GA biosynthesis cause the cessation of runner growth confirming that GA is needed for runner formation (Guttridge and Thompson, 1964; Ramina et al., 1985; Hytönen et al., 2008, 2009). Also the characterization of woodland strawberry mutants support the key role of GA in the control of axillary meristem fate. Recessive mutation causes runnerless phenotype in woodland strawberry (Brown and Wareing, 1965), and a 9-bp deletion in a gene encoding GA biosynthetic enzyme GA20-oxidase (FvGA20ox4) has been found as putative causal locus. This mutated enzyme is not able to convert $\mathrm{GA}_{12}$ to $\mathrm{GA}_{20}$ that is the precursor of bioactive $\mathrm{GA}_{1}$ providing plausible evidence that FvGA20ox4 is the causal gene (Tenreira et al., 2017), although the presence of three other GA20ox genes in the woodland strawberry genome leaves some open questions (Mouhu et al., 2013). EMS mutagenesis screen has revealed another mutation that restores runner formation in the runnerless mutant. The gene is called SRL (Suppressor of Runnerless), and it encodes a DELLA growth repressor of the GA signaling pathway (Caruana et al., 2018). RNAi-silencing of the same gene by another group provides additional evidence about the role of GA signalling in the control of axillary meristem fate ( $\mathrm{Li}$ et al., 2018)

The functional analysis of the flowering time gene FvSOC1 have revealed its additional role in the control of axillary meristem fate. Results from transgenic lines show that FvSOC1 promotes the expression of several GA biosynthetic genes including FvGA20ox4 indicating that FvSOC1 may mediate the photoperiodic control of axillary meristem fate through GA biosynthetic genes in woodland strawberry (Mouhu et al., 2013). This is also supported by the finding that the level of bioactive $\mathrm{GA}_{1}$ is higher in LD-grown axillary buds compared with SD-grown buds in garden strawberry (Hytönen et al., 2009). Based on available evidence, we suggest a model that FvSOC1 may activate FvGA20ox4 and possibly other GA biosynthetic genes in axillary meristems in $\mathrm{LD}$ conditions, which leads to high bioactive $\mathrm{GA}_{1}$ levels, degradation of SLR proteins and runner formation (Fig. 2). Additional QTLs for runner production have also been found in both woodland strawberry and garden strawberry, but causal genes remain unknown (Samad et al., 2017; Hossain et al., 2019).

\section{Dormancy and Chilling Requirements}

Rohde and Bhalerao (2007) define dormancy as "inability to initiate growth from meristems under favourable conditions". According to this definition, there is no dormancy in garden strawberry as they do not completely pause the growth. Stunted growth habit and slow growth after flower initiation in autumn has been described as a dormant stage (Arney, 1955; Battey et al., 1998), although it would be better to refer the slowdown of the growth as "semi-dormancy" (Kurokura et al., 2013). However, similarly to plants with "true dormancy", strawberries possess a chilling requirement meaning that they need to accumulate certain number of hours of cold to resume normal growth after winter (Kronenberg and Wassenaar, 1972; Tehranifar et al., 1998). Interesting differences, however, have been observed in the winter phenology of strawberry species. Garden strawberry and one of its diploid ancestors, woodland strawberry, maintain some green leaves over winter, while other putative diploid ancestors F. iinumae, F. nipponica, and F. viridis shed leaves in autumn (Sargent et al., 2004; Åström et al., 2015; Edger et al., 2019). Whether these three species also have deeper dormancy remains to be tested.

SDs and relatively high temperatures $\left(15^{\circ} \mathrm{C}\right)$ most efficiently induce "dormancy" in garden strawberry and woodland strawberry, while cool temperature of $6^{\circ} \mathrm{C}$ nullifies the effect of SDs (Sønsteby and Heide, 2006, 2011). Six to ten weeks of chilling below $7-10^{\circ} \mathrm{C}$ is needed to recover the growth capacity (Kronenberg and Wassenaar, 1972; Tehranifar et al., 1998; Sønsteby and Heide, 2006). Also daylength extension with low light intensity can resume vigor (Lieten, 1997), but low red to far-red ratio is needed for this LD response (VincePrue et al., 1976).

Molecular regulation of dormancy has been extensively studied in rosaceous fruit trees. One of the significant contributions is the analysis of the genetic background of "evergrowing" peach mutant (Rodriquez et al., 1994; Bielenberg et al., 2008). This mutant continues growth even under frost-cold conditions. It has 


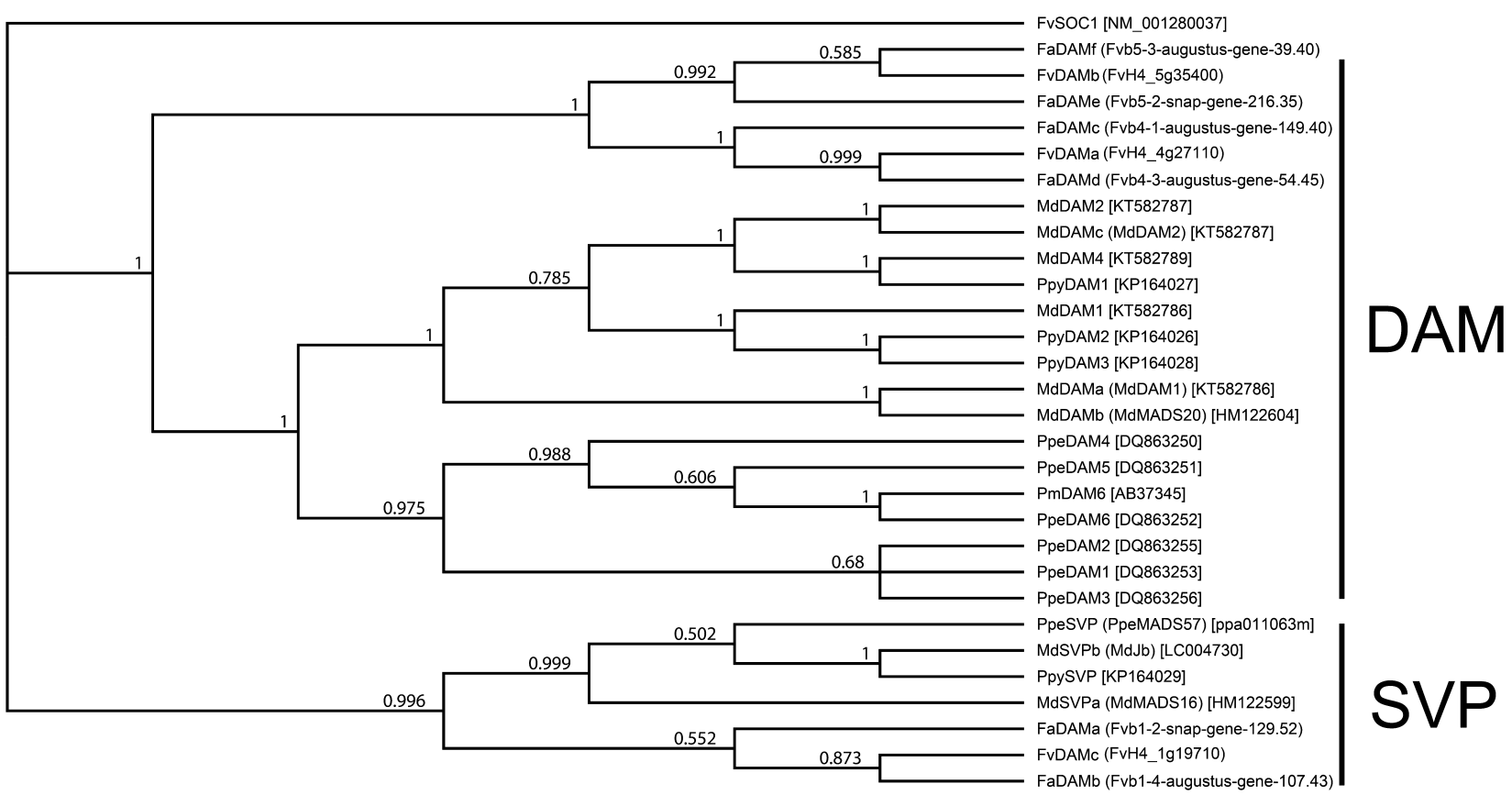

Fig. 4. Phylogenetic tree of Rosaceae DAM/SVP proteins. The tree was built from the full-length amino acid sequence alignment using Clustal Omega program (Madeira et al., 2019) and using Mr. Bayes 3.2.6 program (Huelsenbeck and Ronquist, 2001). FvSOC1 was set as an outgroup. Fragaria DAM/SVP sequences were retrieved by BLAST searches on the predicted proteins of the whole genome of $F$. vesca (Shulaev et al., 2011) and F. $\times$ ananassa (Edger et al., 2019). Fa, F. $\times$ ananassa, Fv, F. vesca, Md, M. domestica, Ppe, P. persica, Ppy, P. pyrifolia. Figures above each branch indicate posterior probability.

been proposed that the causal gene is located within a tandem array of six MADS-box genes called Dormancy-Associated MADS-BOX (DAM) that are all lacking in evergrowing mutant (Bielenberg et al., 2008). DAM sequence is similar to SHORT VEGETATIVE PHASE (SVP), another MADS-box gene of Arabidopsis that functions as a floral repressor (Hartmann et al., 2000; Lee et al., 2007). DAM genes can be classified as pre-, during-, and post-dormancy expressed genes (Mazzitelli et al., 2007; Li et al., 2009; Sasaki et al., 2011; Falavigna et al., 2019), indicating the functional differentiation among them. Recent study has shown that the overexpression of two apple DAMlike genes delays bud break in apple further supporting the role of DAM genes in the control of dormancy (Wu et al., 2017). Several DAM homologs are present also in the genomes of the woodland strawberry and the garden strawberry (Fig. 4) indicating that DAM homologs play important roles in the control of "semi-dormancy" in strawberry. Functional studies on $D A M$ genes and on their regulation are needed to confirm this hypothesis. Such studies are quite advanced in other rosaceous species and should pave a way for research in strawberry.

Apple trees overexpressing a peach $C B F$ gene show alteration in the timing of the bud break as well as the upregulation of some $D A M$ genes indicating that $\mathrm{CBF}$ regulates $D A M$ genes in response to cold exposure (Wisniewski et al., 2015). According to yeast-1-hybrid and transient gene expression assays, pear CBF tran- scription factor, that is upregulated by cool temperatures, binds to $D A M$ promoter region to induce its expression (Niu et al., 2015; Saito et al., 2015). Longer exposure to cool temperatures activate the expression of miR6390 that can target DAM mRNA for degradation, which is associated with increased FT2 mRNA levels and dormancy release (Niu et al., 2015). Also epigenetic mechanisms other than miRNAs are likely involved in the control of $D A M$ expression. H3K27me3 histone marks are deposited on the $D A M$ sequence during cold treatment in a locus specific manner (Leida et al., 2012; De la Fuente et al., 2015). Also Arabidopsis MADSbox gene, floral repressor FLOWERING LOCUS C $(F L C)$, is gradually downregulated by cold by a molecular mechanism including epigenetic modifications of histones and anti-sense transcripts (Swiezewski et al., 2009; Costa and Dean, 2019; Tian et al., 2019), and these studies should pave a way for future research on the epigenetic regulation of $D A M$ expression. Coldregulated $F L C$-like genes have also been reported in apple (Porto et al., 2015; Kumar et al., 2016), but no functional validation has been carried out.

\section{Future Prospects}

Timing, duration and abundance of flowering are traits of major importance for profitable strawberry production. Although several genes controlling flowering and shoot architecture in strawberries have been identified and functionally characterized, more detail understanding on the control of reproductive development 
would have a major impact on the worldwide production of this important berry crop. Studies in both woodland strawberry and garden strawberry have demonstrated the role of TFL1 as a key floral repressor that confers seasonal flowering habit of SD strawberries (Koskela et al., 2012, 2016). Clearly, elucidating the transcriptional regulation of this gene is crucial for understanding environmental flowering responses in seasonal flowering strawberries. Further research on the photoperiodic and temperature regulation of TFL1 is needed to uncover mechanisms that enable strawberry production in different photoperiodic conditions at different latitudes and during different seasons. Another major research topic is to explore genes and molecular mechanisms that control perpetual flowering in garden strawberry. The most burning question is the molecular nature of the dominant floral activator PFRU, but it is also important to find its predicted epistatic regulators and to understand how they are connected to the emerging flowering pathways (Gaston et al., 2013; Lewers et al., 2019).

Understanding the trade-off between flowering and runnering is an important area of research because it would allow plant breeders and growers to control the balance between vegetative and generative reproduction. Although the role of GA as an activator of runner production is clear (Hytönen et al., 2009; Mouhu et al., 2013; Tenreira et al., 2017; Caruana et al., 2018), more research is needed to understand spatiotemporal regulation of GA pathway that determines whether axillary meristems produce runners or branch crowns that provide additional sites for inflorescences. Future studies should identify and characterize transcription factors that control the expression of FvGA20ox4 that encodes putative rate limiting enzyme in the production of bioactive GA in axillary buds (Tenreira et al., 2017). Since the sensitivity of axillary meristems to bioactive GAs is also reduced by SDs (Hytönen et al., 2009), studies on the control of GA signalling are important to understand the control of strawberry plant architecture.

Woodland strawberry has proved to be an efficient model system for the identification and functional characterization of genes controlling reproductive traits (e.g. Koskela et al., 2012; Tenreira et al., 2017; Caruana et al., 2018). It is one of the subgenome donors of the allo-octoploid garden strawberry and its parental species $F$. virginiana and $F$. chiloensis (Tennessen et al., 2014; Sargent et al., 2016; Edger et al., 2019), and according to recent octoploid strawberry genome paper, $F$. vesca genome dominates over other subgenomes in the control of some traits (Edger et al., 2019). Therefore, we hypothesize that studies on natural variation in woodland strawberry populations along its wide geographical distribution could be very successful in the identification of genetic variation controlling reproductive development and other important traits. Recent development of genome editing protocols for woodland strawberry is expected to enable more efficient functional validation of newly identified candidate genes (Zhou et al., 2018; Wilson et al., 2019). These knowledge could facilitate the development of gene-specific markers for important traits in garden strawberry, the screening of genetic variation in wild octoploid species and their utilization in cultivar breeding through introgressions, as well as targeted breeding using genome editing (Martín-Pizarro et al., 2018; Wilson et al., 2019).

\section{Literature Cited}

Ahmadi, H., R. S. Bringhurst and V. Voth. 1990. Modes of inheritance of photoperiodism in Fragaria. J. Amer. Soc. Hort. Sci. 115: 146-152.

Andrés, F. and G. Coupland. 2012. The genetic basis of flowering responses to seasonal cues. Nat. Rev. Genet. 13: 627-639.

Arney, S. E. 1955. Studies of growth and development in the genus Fragaria. IV. Winter growth. Ann. Bot. 19: 265-276.

Åström, H., E. Metsovuori, T. Saarinen, R. Lundell and H. Hänninen. 2015. Morphological characteristics and photosynthetic capacity of Fragaria vesca L. winter and summer leaves. Flora 215: 33-39.

Battey, N. H., P. LeMiere, A. Tehranifar, C. Chekic, S. Taylor, K. J. Shrives, P. Hadley, A. J. Greenland, J. Darby and M. J. Wilkinson. 1998. Genetic and environmental control of flowering in strawberry. p. 111-131. In: K. E. Cockshull, D. Gray, G. B. Seymour, B. Thomas (eds.). Genetic and environmental manipulation of horticultural crops. CABI Publishing, Wallingford.

Bielenberg, D. G., Y. Wang, Z. Li, T. Zhebentyayeva, S. Fan, G. L. Reighard, R. Scorza and A. G. Abbott. 2008. Sequencing and annotation of the evergrowing locus in peach [Prunus persica (L.) Batsch] reveals a cluster of six MADSbox transcription factors as candidate genes for regulation of terminals bud formation. Tree Genet. Genomes 4: 495-507.

Bradford, E., J. F. Hancock and R. M. Warner. 2010. Interactions of temperature and photoperiod determine expression of repeat flowering in strawberry. J. Amer. Soc. Hort. Sci. 135: 102-107.

Bradley, D., O. Ratcliffe, C. Vincent, R. Carpenter and E. Coen. 1997. Inflorescence commitment and architecture in Arabidopsis. Science 275: 80-83.

Bringhurst, R. S. and V. Voth. 1981. Selecting and testing dayneutral strawberries. HortSci. 16: 427.

Brown, T. and P. F. Wareing. 1965. The genetical control of the everbearing habit and three other characters in varieties of Fragaria vesca. Euphytica 14: 97-112.

Caruana, J. C., J. W. Sittmann, W. Wang and Z. Liu. 2018. Suppressor of Runnerless encodes a DELLA protein that controls runner formation for asexual reproduction in strawberry. Mol. Plant 11: 230-233.

Castro, P., J. M. Bushakra, P. Stewart, C. K. Weebadde, D. Wang, J. F. Hancock, C. E. Finn, J. J. Luby and K. S. Lewers. 2015. Genetic mapping of day-neutrality in cultivated strawberry. Mol. Breed. 35: 1-16.

Chen, X. D., J. Wang, M. Z. Zhao and F. Zhao. 2018. Characterization and expression analysis of circadian clock genes in the diploid woodland strawberry Fragaria vesca. Biol. Plant. 62: 451-461.

Cho, L., J. Yoon and G. An. 2017. The control of flowering time by environmental factors. Plant J. 90: 708-719.

Costa, S. and C. Dean. 2019. Storing memories: the distinct 
phases of Polycomb-mediated silencing of Arabidopsis FLC. Biochem. Soc. Trans. 47: 1187-1196.

Costes, E., L. Crespel, B. Denoyes, P. Morel, M. Demene, P. Lauri and B. Wenden. 2014. Bud structure, position and fate generate various branching patterns along shoots of closely related Rosaceae species: a review. Front. Plant Sci. 5: 666.

Dale, A., J. J. Luby and J. F. Hancock. 2002. Breeding dayneutral strawberries for Northern North America. Acta Hort. 567: $133-136$.

Darrow, G. M. 1966. The Strawberry. History, breeding and physiology. Holt, Reinhart and Winston, New York, NY, USA.

Darrow, G. M. and G. F. Waldo. 1934. Responses of strawberry varieties and species to duration of the daily light period. U.S. Department of Agriculture Technical Bulletin. No. 453.

De la Fuente, L., A. Conesa, A. Lloret, M. Badenes and G. Ríos. 2015. Genome-wide changes in histone H3 lysine 27 trimethylation associated with bud dormancy release in peach. Tree Genet. Genomes 11: 45.

Downs, R. J. and A. A. Piringer. 1955. Differences in photoperiodic response of everbearing and June-bearing strawberries. Proc. Amer. Soc. Hort. Sci. 66: 234-236.

Durner, E. F., J. A. Barden, D. G. Himelrick and E. B. Poling. 1984. Photoperiod and temperature effects on flower and runner development in day-neutral, June-bearing and everbearing strawberries. J. Amer. Soc. Hort. Sci. 109: 396-400.

Edger, P. P., T. J. Poorten, R. VanBuren, M. A. Hardigan, M. Colle, M. R. McKain, R. D. Smith, S. J. Teresi, A. D. L. Nelson, C. M. Wai, E. I. Alger, K. A. Bird, A. E. Yocca, N. Pumplin, S. Ou, G. Ben-Zvi, A. Brodt, K. Baruch, T. Swale, L. Shiue, C. B. Acharya, G. S. Cole, J. P. Mower, K. L. Childs, N. Jiang, E. Lyons, M. Freeling, J. R. Puzey and S. J. Knapp. 2019. Origin and evolution of the octoploid strawberry genome. Nat. Genet. 51: 541-547.

Falavigna, V. S., B. Guitton, E. Costes and F. Andrés. 2019. I Want to (bud) break free: the potential role of DAM and $S V P$-like genes in regulating dormancy cycle in temperate fruit trees. Front. Plant Sci. 9: 1990.

Flachowsky, H., I. Szankowski, S. Waidmann, A. Peil, C. Tränkner and M. Hanke. 2012. The MdTFL1 gene of apple (Malus $\times$ domestica Borkh.) reduces vegetative growth and generation time. Tree Phys. 32: 1288-1301.

Freiman, A., L. Shlizerman, S. Golobovitch, Z. Yablovitz, R. Korchinsky, Y. Cohen, A. Samach, E. Chevreau, P. Le Roux, A. Patocchi and M. A. Flaishman. 2012. Development of a transgenic early flowering pear (Pyrus communis L.) genotype by RNAi silencing of PcTFL1-1 and PcTFL1-2. Planta 235: 1239.

Gaston, A., J. Perrotte, E. Lerceteau-Köhler, M. RousseauGueutin, A. Petit, M. Hernould, C. Rothan and B. Denoyes. 2013. $P F R U$, a single dominant locus regulates the balance between sexual and asexual plant reproduction in cultivated strawberry. J. Exp. Bot. 64: 1837-1848.

Guttridge, C. G. 1959. Further evidence for a growth-promoting and flower-inhibiting hormone in strawberry. Ann. Bot. 23: 612-621.

Guttridge, C. G. and P. A. Thompson. 1964. The effect of gibberellins on growth and flowering of Fragaria and Duchesnea. J. Exp. Bot. 15: 631-646.

Hancock, J. F., P. P. Edger, P. W. Callow, T. Herlache and C. E. Finn. 2018. Generating a unique germplasm base for the breeding of day-neutral strawberry cultivars. HortSci. 53: 1069-1071.

Hardigan, M. A., T. J. Poorten, C. B. Acharya, G. S. Cole, K. E. Hummer, N. Bassil, P. P. Edger and S. J. Knapp. 2018. Domestication of temperate and coastal hybrids with distinct ancestral gene selection in octoploid strawberry. Plant Genome 11: 180049.

Hartmann, H. T. 1947. Some effects of temperature and photoperiod on flower formation and runner production in the strawberry. Plant Physiol. 22: 407-420.

Hartmann, U., S. Höhmann, K. Nettesheim, E. Wisman, H. Saedler and P. Huijser. 2000. Molecular cloning of SVP: a negative regulator of the floral transition in Arabidopsis. Plant J. 21: 351-360.

Heide, O. M. 1977. Photoperiod and temperature interactions in growth and flowering of strawberry. Physiol. Plant. 40: 2126.

Heide, O. M. and A. Sønsteby. 2007. Interactions of temperature and photoperiod in the control of flowering of latitudinal and altitudinal populations of wild strawberry (Fragaria vesca). Physiol. Plant. 130: 280-289.

Heide, O. M., J. A. Stavang and A. Sønsteby. 2013. Physiology and genetics of flowering in cultivated and wild strawberries -A review. J. Hort. Sci. Biotech. 88: 1-18.

Hilmarsson, H. S., T. Hytönen, S. Isobe, M. Göransson, T. Toivainen and J. H. Hallsson. 2017. Population genetic analysis of a global collection of Fragaria vesca using microsatellite markers. PLoS ONE 12: e0183384.

Honjo, M., T. Nunome, S. Kataoka, T. Yano, M. Hamano, H. Yamazaki, T. Yamamoto, M. Morishita and S. Yui. 2016. Simple sequence repeat markers linked to the everbearing flowering gene in long-day and day-neutral cultivars of the octoploid cultivated strawberry Fragaria $\times$ ananassa. Euphytica 209: 291-303.

Hossain, M. R., S. Natarajan, H. Kim, D. M. I. Jesse, C. Lee, J. Park and I. Nou. 2019. High density linkage map construction and QTL mapping for runner production in allooctoploid strawberry Fragaria $\times$ ananassa based on ddRADseq derived SNPs. Sci. Rep. 9: 3275.

Huelsenbeck, J. P. and F. Ronquist. 2001. MRBAYES: Bayesian inference of phylogenetic trees. Bioinformatics 17: 754-755.

Hytönen, T., P. Elomaa, T. Moritz and O. Junttila. 2009. Gibberellin mediates daylength controlled differentiation of vegetative meristems in strawberry (Fragaria $\times$ ananassa Duch.). BMC Plant Biol. 9: 18.

Hytönen, T., K. Mouhu, I. Koivu and O. Junttila. 2008. Planting year prohexadione-calcium treatment increases the cropping potential and yield of strawberry (Fragaria $\times$ ananassa Duch.). Eur. J. Hort. Sci. 73: 210-215.

Hytönen, T., P. Palonen, K. Mouhu and O. Junttila. 2004. Crown branching and cropping potential in strawberry (Fragaria ananassa Duch.) can be enhanced by daylength treatments. J. Hort. Sci. Biotech. 79: 466-471.

Ito, H. and T. Saito. 1962. Studies on the flower formation in the strawberry plant. I. Effects of temperature and photoperiod on the flower formation. Tohoku J. Agric. Res. 13: 191-203.

Iwata, H., A. Gaston, A. Remay, T. Thouroude, J. Jeauffre, K. Kawamura, L. Hibrand-Saint Oyant, T. Araki, B. Denoyes and F. Foucher. 2012. The TFL1 homologue KSN is a regulator of continuous flowering in rose and strawberry. Plant J. 69: 116-125.

Konsin, M., I. Voipio and P. Palonen. 2001. Influence of photoperiod and duration of short-day treatment on vegetative growth and flowering of strawberry (Fragaria $\times$ ananassa Duch.). J. Hort. Sci. Biotech. 76: 77-82.

Koskela, E. A., T. Kurokura, T. Toivainen, A. Sønsteby, O. M. Heide, D. J. Sargent, S. Isobe, L. Jaakola, H. Hilmarsson, P. Elomaa and T. Hytönen. 2017. Altered regulation of TERMINAL FLOWER 1 causes the unique vernalisation response in an arctic woodland strawberry accession. New 
Phytol. 216: 841-853.

Koskela, E., K. Mouhu, M. C. Albani, T. Kurokura, M. Rantanen, D. Sargent, N. H. Battey, G. Coupland, P. Elomaa and T. Hytönen. 2012. Mutation in TERMINAL FLOWER1 reverses the photoperiodic requirement for flowering in the wild strawberry, Fragaria vesca. Plant Physiol. 159: 1043-1054.

Koskela, E., A. Sønsteby, H. Flachowsky, O. Heide, V. Hanke, P. Elomaa and T. Hytönen. 2016. TERMINAL FLOWER 1 is a breeding target for a novel everbearing trait and tailored flowering responses in cultivated strawberry Fragaria $\times$ ananassa Duch.). Plant Biotech. J. 14: 1852-1861.

Kotoda, N., H. Iwanami, S. Takahashi and K. Abe. 2006. Antisense expression of MdTFL1, a TFL1-like gene, reduces the juvenile phase in apple. J. Amer. Soc. Hort. Sci. 131: 74-81.

Kronenberg, H. G. and L. M. Wassenaar. 1972. Dormancy and chilling requirement of strawberry varieties for early forcing. Euphytica 21: 454.

Kumar, G., P. Arya, K. Gupta, V. Randhawa, V. Acharya and A. K. Singh. 2016. Comparative phylogenetic analysis and transcriptional profiling of MADS-box gene family identified DAM and FLC-like genes in apple (Malus $\times$ domestica). Sci. Rep. 6: 20695

Kurokura, T., T. Iwama, Y. Inaba and N. Sugiyama. 2005. Effect of day-length on the developmental pattern of axillary buds in June-bearing strawberry plants. J. Hort. Sci. Biotech. 80: 139-142.

Kurokura, T., N. Mimida, N. H. Battey and T. Hytönen. 2013. The regulation of flowering in the Rosaceae. J. Exp. Bot. 64: 4131-4141.

Kurokura, T., S. Samad, K. Mouhu, E. Koskela and T. Hytönen. 2017. Fragaria vesca CONSTANS controls photoperiodic flowering and vegetative development. J. Exp. Bot. 68: 4839-4850.

Le Mière, P., P. Hadley, J. Darby and N. H. Battey. 1996. The effect of temperature and photoperiod on the rate of flower initiation and the onset of dormancy in the strawberry (Fragaria $\times$ ananassa Duch.). J. Hort. Sci. 71: 361-371.

Lee, J. H., S. J. Yoo, S. H. Park, I. Hwang, J. S. Lee and J. H. Ahn. 2007. Role of SVP in the control of flowering time by ambient temperature in Arabidopsis. Genes Dev. 21: 397402.

Leida, C., A. Conesa, G. Llácer, M. L. Badenes and G. Ríos. 2012. Histone modifications and expression of DAM6 gene in peach are modulated during bud dormancy release in a cultivar dependent manner. New Phytol. 193: 67-80.

Lewers, K. S., P. Castro, J. F. Hancock, C. K. Weebadde, J. V. Die and L. J. Rowland. 2019. Evidence of epistatic suppression of repeat fruiting in cultivated strawberry. BMC Plant Biol. 19: 386

Li, W., J. Zhang, H. Sun, S. Wang, K. Chen, Y. Liu, H. Li, Y. Ma and Z. Zhang. 2018. FveRGA1, encoding a DELLA protein, negatively regulates runner production in Fragaria vesca. Planta 247: 941.

Li, Z., G. L. Reighard, A. G. Abbott and D. G. Bielenberg. 2009. Dormancy-associated MADS box genes from the EVG locus of peach have distinct seasonal and photoperiodic expression patterns. J. Exp. Bot. 60: 3521-3530.

Lieten, F. 1997. Effects of chilling and night-break treatment on greenhouse production of 'Elsanta'. Acta Hort. 439: 633640.

Liston, A., R. Cronn and T. L. Ashman. 2014. Fragaria: A genus with deep historical roots and ripe for evolutionary and ecological insights. Amer. J. Bot. 101: 1686-1699.

Madeira, F., Y. M. Park, J. Lee, N. Buso, T. Gur, N. Madhusoodanan, P. Basutkar, A. R. N. Tivey, S. C. Potter,
R. D. Finn and R. Lopez. 2019. The EMBL-EBI search and sequence analysis tools APIs in 2019. Nucleic Acids Res. 47: W636-W641.

Manakasem, Y. and P. B. Goodwin. 2001. Responses of dayneutral and Junebearing strawberries to temperature and daylength. J. Hort. Sci. Biotech. 76: 629-635.

Martín-Pizarro, C., J. C. Triviño and D. Posé. 2018. Functional analysis of the TM6 MADS-box gene in the octoploid strawberry by CRISPR/Cas9-directed mutagenesis. J. Exp. Bot. 70: 885-895.

Mazzitelli, L., R. D. Hancock, S. Haupt, P. G. Walker, S. D. Pont, J. McNicol, J. Morris, R. Viola, R. Brennan, P. E. Hedley and M. A. Taylor. 2007. Co-ordinated gene expression during phases of dormancy release in raspberry (Rubus idaeus L.) buds. J. Exp. Bot. 58: 1035-1045.

Mookerjee, S., M. M. Mathey, C. E. Finn, Z. Zhang and J. F. Hancock. 2013. Heat tolerance plays an important role in regulating remontant flowering in an F1 population of octoploid strawberry (Fragaria $\times$ ananassa). J. Berry Res. 3: $151-158$.

Mouhu, K., T. Hytönen, K. Folta, M. Rantanen, L. Paulin, P. Auvinen and P. Elomaa. 2009. Identification of flowering genes in strawberry - a perennial rosette plant. BMC Plant Biol. 9: 122.

Mouhu, K., T. Kurokura, E. Koskela, V. A. Albert, P. Elomaa and T. Hytönen. 2013. Fragaria vesca homolog of SUPPRESSOR OF OVEREXPRESSION OF CONSTANS1 represses flowering and promotes vegetative growth. Plant Cell 25: 3296-3310.

Nakano, Y., Y. Higuchi, Y. Yoshida and T. Hisamatsu. 2015. Environmental responses of the FT/TFL1 gene family and their involvement in flower induction in Fragaria $\times$ ananassa. J. Plant Physiol. 177: 60-66.

Nishiyama, M. and K. Kanahama. 2000. Effects of temperature and photoperiod on the development of inflorescences in everbearing strawberry (Fragaria $\times$ ananassa Duch.) plants. Acta Hort. 514: 261-267.

Nishiyama, M., W. Ohkawa and K. Kanahama. 2003. Effect of photoperiod on the development of inflorescences in everbearing strawberry 'Summerberry' plants grown at high temperature. Tohoku J. Agric. Res. 53: 43-52.

Niu, Q., J. Li, D. Cai, M. Qian, H. Jia, S. Bai, S. Hussain, G. Liu, Y. Teng and X. Zheng. 2015. Dormancy-associated MADSbox genes and microRNAs jointly control dormancy transition in pear (Pyrus pyrifolia white pear group) flower bud. J. Exp. Bot. 67: 239-257.

Perrotte, J., A. Gaston, A. Potier, A. Petit, C. Rothan and B. Denoyes. 2016. Narrowing down the single homoeologous FaPFRU locus controlling flowering in cultivated octoploid strawberry using a selective mapping strategy. Plant Biotech. J. 4: 1-14

Porto, D. D., M. Bruneau, P. Perini, R. Anzanello, J. Renou, H. Pessoa dos Santos, F. B. Fialho and L. F. Revers. 2015. Transcription profiling of the chilling requirement for bud break in apples: a putative role for $F L C$-like genes. J. Exp. Bot. 66: 2659-2672.

Ramina, A., P. Tonutti and T. Tosi. 1985. The effect of paclobutrazol on strawberry growth and fruiting. J. Hort. Sci. 60: 501-506.

Rantanen, M., T. Kurokura, P. Jiang, K. Mouhu and T. Hytönen. 2015. Strawberry homolog of TERMINAL FLOWER1 integrates photoperiod and temperature signals to inhibit flowering. Plant J. 82: 163-173.

Rantanen, M., T. Kurokura, K. Mouhu, P. Pinho, E. Tetri, L. Halonen, P. Palonen, P. Elomaa and T. Hytönen. 2014. Light 
quality regulates flowering in FvFT1/FvTFL1 dependent manner in the woodland strawberry Fragaria vesca. Front. Plant Sci. 5: 271.

Rodriquez, A. J., W. B. Sherman, R. Scorza, M. Wisniewski and W. R. Okie. 1994. 'Evergreen' peach, its inheritance and dormant behavior. J. Amer. Soc. Hort. Sci. 119: 789-792.

Rohde, A. and R. P. Bhalerao. 2007. Plant dormancy in the perennial context. Trends Plant Sci. 12: 217-223.

Saito, T., S. Bai, T. Imai, A. Ito, I. Nakajima and T. Moriguchi. 2015. Histone modification and signalling cascade of the dormancy-associated MADS-box gene, PpMADS13-1, in Japanese pear (Pyrus pyrifolia) during endodormancy. Plant Cell Environ. 38: 1157-1166.

Salinas, N. R., J. D. Zurn, M. Mathey, S. Mookerjee, B. Denoyes, J. Perrotte, A. Potier, C. E. Finn, J. F. Hancock, P. Stewart and N. V. Bassil. 2017. Validation of molecular markers associated with perpetual flowering in octoploid Fragaria germplasm. Mol. Breed. 37: 70.

Samad, S., T. Kurokura, T. Toivainen, V. Patel, D. J. Sargent and T. Hytönen. 2017. Additive QTLs on three chromosomes control flowering time in strawberry. Hort. Res. 4: 17020.

Sargent, D. J., M. Geibel, J. A. Hawkins, M. J. Wilkinson, N. H. Battey and D. W. Simpson. 2004. Quantitative and qualitative differences in morphological traits revealed between diploid Fragaria species. Ann. Bot. 94: 787-796.

Sargent, D. J., Y. Yang, N. Šurbanovski, L. Bianco, M. Buti, R. Velasco, L. Giongo and T. M. Davis. 2016. HaploSNP affinities and linkage map positions illuminate subgenome composition in the octoploid, cultivated strawberry (Fragaria $\times$ ananassa). Plant Sci. 242: 140-150.

Sasaki, R., H. Yamane, T. Ooka, H. Jotatsu, Y. Kitamura, T. Akagi and R. Tao. 2011. Functional and expressional analyses of PmDAM genes associated with endodormancy in Japanese apricot (Prunus mume). Plant Physiol. 157: 485497.

Sawa, M., D. A. Nusinow, S. A. Kay and T. Imaizumi. 2007. FKF1 and GIGANTEA complex formation is required for day-length measurement in Arabidopsis. Science 318: 261265.

Schwarz, S., A. V. Grande, N. Bujdoso, H. Saedler and P. Huijser. 2008. The microRNA regulated SBP-box genes SPL9 and SPL15 control shoot maturation in Arabidopsis. Plant Mol. Biol. 67: 183-195.

Serçe, S. and J. F. Hancock. 2005. Inheritance of day-neutrality in octoploid species of Fragaria. J. Amer. Soc. Hort. Sci. 130: 580-584.

Shaw, D. V. and T. R. Famula. 2005. Complex segregation analysis of day-neutrality in domestic strawberry (Fragaria $\times$ ananassa Duch.). Euphytica 145: 331-338.

Shulaev, V., D. J Sargent, R. N. Crowhurst, T. C. Mockler, O. Folkerts, A. L. Delcher, P. Jaiswal, K. Mockaitis, A. Liston, S. P. Mane, P. Burns, T. M. Davis, J. P. Slovin, N. Bassil, R. P. Hellens, C. Evans, T. Harkins, C. Kodira, B. Desany, O. R. Crasta, R. V. Jensen, A. C. Allan, T. P. Michael, J. C. Setubal, J.-M. Celton, D. J. G. Rees, K. P. Williams, S. H. Holt, J. J. R. Rojas, M. Chatterjee, B. Liu, H. Silva, L. Meisel, A. Adato, S. A. Filichkin, M. Troggio, R. Viola, T.-L. Ashman, H. Wang, P. Dharmawardhana, J. Elser, R. Raja, H. D. Priest, D. W. Bryant Jr., S. E. Fox, S. A. Givan, L. J. Wilhelm, S. Naithani, A. Christoffels, D. Y. Salama, J. Carter, E. L. Girona, A. Zdepski, W. Wang, R. A. Kerstetter, W. Schwab, S. S. Korban, J. Davik, A. Monfort, B. Denoyes-Rothan, P. Arus, R. Mittler, B. Flinn, A. Aharoni, J. L. Bennetzen, S. L. Salzberg, A. W. Dickerman, R. Velasco, M. Borodovsky, R. E. Veilleux and K. M. Folta.
2011. The genome of woodland strawberry (Fragaria vesca). Nat. Genet. 43: 109-116.

Simpson, D. 2018. The economic importance of strawberry crops. p: 1-7 In: T. Hytönen, J. Graham, R. Harrison (eds.). The genomes of rosaceous berries and their wild relatives. Springer, Cham, Switzerland.

Sønsteby, A. and O. M. Heide. 2006. Dormancy relations and flowering of the strawberry cultivars Korona and Elsanta as influenced by photoperiod and temperature. Sci. Hort. 110: 57-67.

Sønsteby, A. and O. M. Heide. 2007a. Quantitative long-day flowering response in the perpetual-flowering F1 strawberry cultivar Elan. J. Hort. Sci. Biotech. 82: 266-274.

Sønsteby, A. and O. M. Heide. 2007b. Long-day control of flowering in everbearing strawberries. J. Hort. Sci. Biotech. 82: 875-884.

Sønsteby, A. and O. M. Heide. 2008. Temperature responses, flowering and fruit yield of the June-bearing strawberry cultivars Florence, Frida and Korona. Sci. Hort. 119: 49-54.

Sønsteby, A. and O. M. Heide. 2011. Environmental regulation of dormancy and frost hardiness in Norwegian populations of wood strawberry (Fragaria vesca L.). Eur. J. Plant Sci. Biotech. 5: 42-48.

Sønsteby, A. and O. M. Heide. 2017. Flowering performance and yield of established and recent strawberry cultivars (Fragaria $\times$ ananassa) as affected by raising temperature and photoperiod. J. Hort. Sci. Biotech. 92: 367-375.

Suárez-López, P., K. Wheatley, F. Robson, H. Onouchi, F. Valverde and G. Coupland. 2001. CONSTANS mediates between the circadian clock and the control of flowering in Arabidopsis. Nature 410: 1116-1120.

Swiezewski, S., F. Liu, A. Magusin and C. Dean. 2009. Cold induced silencing by long antisense transcripts of an Arabidopsis polycomb target. Nature 462: 799-802.

Tehranifar, A., P. Le Miere and N. H. Battey. 1998. The effects of lifting date, chilling duration and forcing temperature on vegetative growth and fruit production in the Junebearing strawberry cultivar Elsanta. J. Hort. Sci. Biotech. 73: 453460.

Tennessen, J. A., R. Govindarajulu, T. Ashman and A. Liston. 2014. Evolutionary origins and dynamics of octoploid strawberry subgenomes revealed by dense targeted capture linkage maps. Genome Biol. Evol. 6: 3295-3313.

Tenreira, T., M. J. P. Lange, T. Lange, C. Bres, M. Labadie, A. Monfort, M. Hernould, C. Rothan and B. Denoyes. 2017. A specific gibberellin 20-oxidase dictates the floweringrunnering decision in diploid strawberry. Plant Cell 29: 2168-2182.

Tian, Y., H. Zheng, F. Zhang, S. Wang, X. Ji, C. Xu, Y. He and Y. Ding. 2019. PRC2 recruitment and H3K27me3 deposition at FLC require FCA binding of COOLAIR. Sci. Adv. 5: eaau7246.

Urrutia, M., J. Bonet, P. Arús and A. Monfort. 2015. A nearisogenic line (NIL) collection in diploid strawberry and its use in the genetic analysis of morphologic, phenotypic and nutritional characters. Theor. Appl. Genet. 128: 1261.

Valverde, F., A. Mouradov, W. Soppe, D. Ravenscroft, A. Samach and G. Coupland. 2004. Photoreceptor regulation of CONSTANS protein in photoperiodic flowering. Science 303: 1003-1006.

Verheul, M. J., A. Sønsteby and S. O. Grimstad. 2007. Influences of day and night temperatures on flowering of Fragaria $x$ ananassa Duch., cvs. Korona and Elsanta, at different photoperiods. Sci. Hort. 112: 200-206.

Verma, S., J. D. Zurn, N. Salinas, M. M. Mathey, B. Denoyes, 
J. F. Hancock, C. E. Finn, N. V. Bassil and V. M. Whitaker. 2017. Clarifying sub-genomic positions of QTLs for flowering habit and fruit quality in U.S. strawberry (Fragaria $\times$ ananassa) breeding populations using pedigree-based QTL analysis. Hort. Res. 4: 17062.

Vince-Prue, D., C. G. Guttridge and M. W. Buck. 1976. Photocontrol of petiole elongation in light-grown strawberry plants. Planta 131: 109-114.

Wagstaffe, A. and N. H. Battey. 2006. Characterisation of the thermodormancy response in the everbearing strawberry 'Everest'. J. Hort. Sci. Biotech. 81: 1086-1092.

Weebadde, C. K., D. Wang, C. E. Finn, K. S. Lewers, J. J. Luby, J. Bushakra, T. M. Sjulin and J. F. Hancock. 2008. Using a linkage mapping approach to identify QTL for day-neutrality in the octoploid strawberry. Plant Breed. 127: 94-101.

Wilson, F. M., K. Harrison, A. D. Armitage, A. J. Simkin and R. J. Harrison. 2019. CRISPR/Cas9-mediated mutagenesis of phytoene desaturase in diploid and octoploid strawberry. Plant Methods 15: 45.
Wisniewski, M., J. Norelli and T. Artlip. 2015. Overexpression of a peach $C B F$ gene in apple: a model for understanding the integration of growth, dormancy, and cold hardiness in woody plants. Front. Plant Sci. 6: 85.

Wu, R., S. Tomes, S. Karunairetnam, S. D. Tustin, R. P. Hellens, A. C. Allan, R. C. Macknight and E. Varkonyi-Gasic. 2017. $S V P$-like MADS box genes control dormancy and budbreak in apple. Front. Plant Sci. 8: 477

Xiong, J., Y. Bai, C. Ma, H. Zhu, D. Zheng and Z. Cheng. 2019. Molecular cloning and characterization of SQUAMOSApromoter binding protein-like gene FvSPL10 from woodland strawberry (Fragaria vesca). Plants 8: 342.

Xiong, J., D. Zheng, H. Zhu, J. Chen, R. Na and Z. Cheng. 2018. Genome-wide identification and expression analysis of the SPL gene family in woodland strawberry Fragaria vesca. Genome 61: 675-683.

Zhou, J., G. Wang and Z. Liu. 2018. Efficient genome editing of wild strawberry genes, vector development and validation. Plant Biotech. J. 16: 1868-1877. 